\title{
THE ENERGY STORAGE PROBLEM
}

\section{Renewable energy is not a viable option unless energy can be stored on a large scale. David Lindley looks at five ways to do that.}

\begin{abstract}
n February 2008, during a sudden cold snap, the normally relentless winds of west Texas fell silent and the thousands of wind turbines that dot that part of the state slowed to a halt. Local utility operators, unable to make up the shortfall with power from elsewhere in the grid, were forced to cut service to some users for up to an hour and a half before the winds picked up again.

That windless interval would have been a non-event if the utility companies had had a few hundred megawatt hours of energy stored away that they could draw on in emergencies. But they didn't. Ever ephemeral, electrical energy is difficult and expensive to store in large quantities.

The lack of good storage options has plagued utility operators for generations. Obligated to provide a steady supply of electricity to meet constantly varying demand, they have conventionally resorted to the costly and inefficient method of adjusting the output of a coal-fired plant, say, or by turning on a gas-powered 'peaker' plant during periods of high demand.
\end{abstract}

But that supply-based strategy is becoming less viable with the increased use of renewable energy sources with unpredictable output, notably solar arrays and wind farms. As the Texan example indicates, the power produced by these technologies is dependent on nature's whim, not human demand. "If we want to have a significant part of our energy come from renewable sources, storage is a must," says Ali Nourai, manager of energy storage at American Electric Power, a utility company in Columbus, Ohio, and chairman of the Electricity Storage Association, a trade association in Washington DC.

A number of technologies for energy storage already exist, including some that have been around for decades. The challenge is to make them robust, reliable and economically competitive - while matching the most suitable technology to each energy source or location. "Each technology has unique features," says Jillis Raadschelders, of energy consulting firm KEMA in Arnhem, the Netherlands. "There will never be a winning technology." Choosing the right technology means looking at each one in some detail.

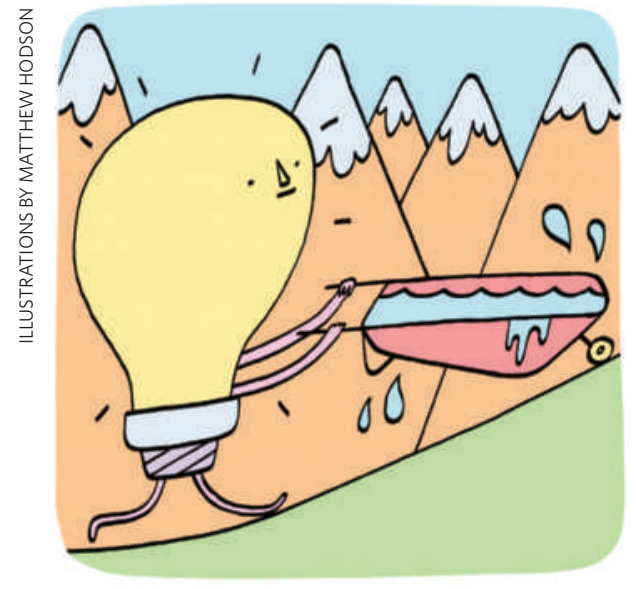

PUSHING WATER UPHILL

The need for storage is particularly acute in densely populated northern Europe, where many countries are building offshore turbines to harness the winds blowing across the North Sea. Denmark already gets about 20\% of its electricity from land- and sea-based wind farms, and it is aiming to increase that figure to $50 \%$ by 2025 . Because the North Sea winds can drop to low levels for days at a time, however, countries such as Denmark and the Netherlands are increasing their grid connectivity to Norway, which gets the vast majority of its power from hydroelectric plants. Norway's mountain reservoirs provide back-up power capacity, and also offer substantial amounts of pumped storage hydroelectricity, in which water is pumped uphill to a reservoir using surplus electricity, and released downhill again to turn a generator when power is needed. Pumped hydroelectricity has a storage efficiency of $70-85 \%$, and it is the most mature and widespread technology being used for large-scale electricity storage. China, Japan and the United States, for example, have numerous installations with generating capacities ranging from tens of megawatts (MW)
"If pumped storage hydroelectricity capacity is to grow significantly, it will have to leave the mountains." hydroelectricity requires mountains, so opportunities are limited by geography. Building such storage also tends to be expensive and environmentally destructive, and installing high-voltage transmission lines to connect remote storage sites to grids often triggers opposition on environmental grounds.

If the capacity of pumped storage hydroelectricity is to grow significantly, it will have to leave the mountains. One innovative concept by KEMA would put wind turbines and to several gigawatts (GW). Pumped storage hydroelectricity is a particularly good match for wind power because water pumped into an upper reservoir will stay there for a long time, making up for potentially large gaps in wind generation.

But in its conventional form, pumped storage pumped hydro in the same place: an 'energy island' in a shallow part of the North Sea. An area of perhaps 60 square kilometres would be ringed off by a dyke or levee to create an artificial lake. Wind turbines would stand on the encircling dyke, and any excess power would be used to pump water out of the lake and into the surrounding sea. Letting sea water flow back in would regenerate the stored electricity. In the absence of wind, KEMA estimates that the energy island could supply an average of 1,500 MW for as long as 12 hours. 


\section{SQUEEZING AIR UNDERGROUND}

In the farmlands near Huntorf, Germany, about 100 kilometres southwest of Hamburg, an ordinary-looking industrial installation performs an unusual task: when demand for electricity in the local grid is low, the plant uses excess power to compress air and pump it into two underground salt caverns with a combined volume of more than 300,000 cubic metres. Then, at times of high demand, the compressed air is allowed to expand through turbines on the surface to regenerate the electricity.

The Huntorf plant, which has been working since 1978, can supply almost $300 \mathrm{MW}$ of reserve power for up to three hours, and comes into operation about 100 times a year. But it has not exactly spawned a legion of imitators. A similar but smaller plant in McIntosh, Alabama, came online in 1991, and efforts to build another such system in Iowa, begun in 2002, are only now at the point of acquiring land for test drilling.

The problem is that these compressed-air energy storage (CAES) facilities are considerably more complex in practice than they are in principle. Gas heats up when it is compressed, which limits how much air can be pumped underground before it becomes too hot to be stored safely. Moreover, the longer that hot air

\section{ELECTRICITY IN A BOX}

Large-scale battery storage would be a solved problem already if utility companies could use the ubiquitous lead-acid technology that has been the basis of car batteries for nearly a century. Unfortunately, lead-acid batteries have a low energy density — they are bulky and heavy for the amount of energy they store - and they do not stand up well to repeated charge-discharge cycles.

A better solution is the sodium-sulphur $(\mathrm{NaS})$ battery, which stores energy by chemically dissociating sodium polysulphide into sodium and sulphur. The energy can then be released by allowing the two elements to react again. NaS batteries have a high energy density and can last through thousands of charge-discharge cycles. Their chief drawback is that the sodium and sulphur have to be kept in separate reservoirs in the molten state, at about $300^{\circ} \mathrm{C}$. Also, the batteries suffer irreparable damage if they discharge completely and grow cold. The resulting need for a robust container, along with other technical requirements, means that $\mathrm{NaS}$ batteries cost about US $\$ 3,000$ per kilowatt $(\mathrm{kW})$ of available power. That compares unfavourably with standard gas-powered plants, which cost about $\$ 1,000 / \mathrm{kW}$. Nonetheless, NaS batteries

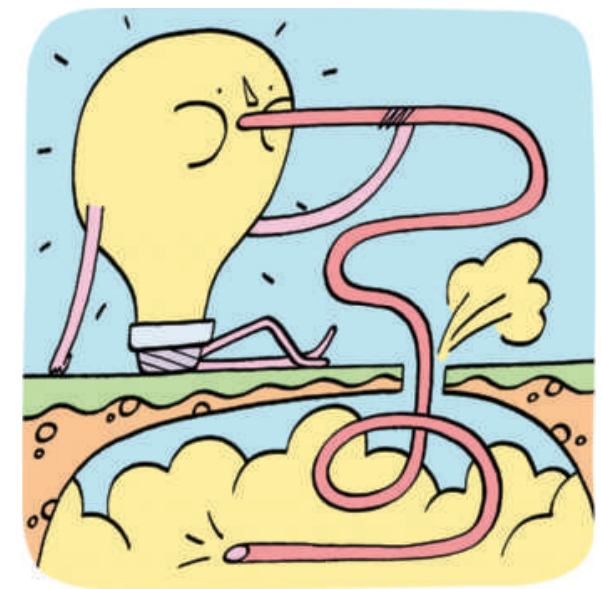

is left in place, the more of its heat - which represents a substantial fraction of the input energy - is lost into the walls of the surrounding cavern. And then when it is released again, the expanding air cools down. In the Huntorf and McIntosh facilities, in fact, the released air is fed into a standard natural gas turbine, boosting its efficiency. So the net effect of the air-compression system is to boost the efficiency of a more or less conventional natural-gas-fuelled power plant.

In the near term this kind of hybrid system "makes a great deal of sense", says Haresh

have been developed commercially by NGK Insulators in Nagoya, Japan. Japan now has an installed capacity able to supply its grid with about $300 \mathrm{MW}$ when extra power is needed, for up to six hours at a stretch. Other countries are also picking up the pace. The United States, for example, has about $10 \mathrm{MW}$ of NaS capacity in place and a similar amount on the way, led by companies such as American Electric Power and Xcel Energy in Minneapolis, Minnesota.

In the future, large-scale $\mathrm{NaS}$ storage could face a challenge from lithium-ion technology. Already in widespread use for mobile phones and laptops, and under development for electric cars, lithium-ion batteries have a high energy density and efficiencies of more than $90 \%$. Their big drawback is cost, which is in part driven by safety considerations: the batteries use a lithium salt in an organic solution, which is flammable, necessitating robust construction to minimize fire hazards. Lithium-ion batteries made for consumer electronics currently cost a few hundred dollars per stored kW hour. But for widespread vehicle applications, that cost must come down closer to $\$ 100$ per $\mathrm{kW}$ hour, and for grid applications it needs to be lower still.

Yet Nourai, for one, remains optimistic. Safety issues are more easily and cheaply met
Kamath, a researcher at the Electric Power Research Institute (EPRI) in Palo Alto, California, especially as more electricity from renewable sources is available to recharge the system at night. Looking further down the road, however, the EPRI and others are also researching improvements that would turn CAES into a true energy storage system, requiring no fossil fuel. Such an 'advanced adiabatic' system would capture and store the heat of compression and then use it to reheat the released air, which would spin a turbine directly without any additional fuel. Metal foundries and blast furnaces have for years captured waste heat in stacks of refractory bricks or similar materials, says Christoph Jakiel, a researcher at MAN Turbo in Oberhausen, Germany. So applying the technique to compressed-air storage should be straightforward.

He estimates that the efficiency of such a system to be something under $80 \%$, comparable with pumped storage hydroelectric systems. The overall costs of construction and operation would also be about the same. Suitable locations should not be hard to find in most regions of the world, says Jakiel. Salt caverns are not uncommon, and the proposed Iowa Stored Energy Park, should it ever be built, will pump compressed air into an aquifer.

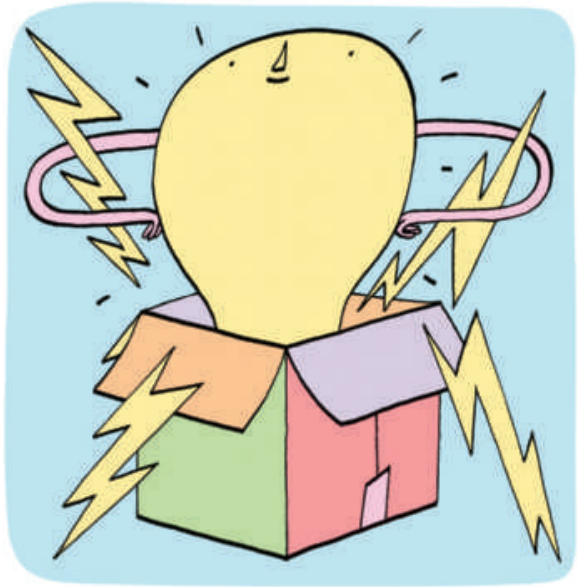

for batteries in secure, fixed installations than in hand-held devices, he says. And in Asia, especially, there is strong support for lithium-ion technology and keen competition between manufacturers, which he hopes will lead to dramatic cost reductions. In China, he recently saw a cargo-container-sized lithiumion installation, and expects to see capacities of a megawatt or more in the coming years.

At the Massachusetts Institute of Technology in Cambridge, materials chemist Donald Sadoway 
is trying a more radical approach to reducing the cost. "I want a battery that's dirt cheap," says Sadoway, "and the way to do it is to build it from dirt" - that is, from the most abundant elements in Earth's crust. Although there is little new to discover about the electrochemistry of these

\section{TAKING ELECTRICITY FOR A SPIN}

Conceptually, at least, one of the most straightforward ways to store energy is in a spinning flywheel: electrical energy gets converted into the kinetic energy of rotation by running it through a motor, which accelerates the flywheel. And the kinetic energy is extracted when it is needed by coupling the flywheel to a generator, which slows the wheel down and produces electricity.

Again, however, the reality is more complex - the flywheel has to spin very fast yet be strong enough to keep from flying apart. Flywheel storage systems are commercially available as uninterruptible power supplies that can deliver modest amounts of power for seconds or minutes, but they are not competitive for the longer storage times needed by the electric utility companies.

One big advantage of flywheels is that they can absorb the energy within seconds or minutes, and give it back just as quickly. This is exactly what is needed for regulating the frequency of a power grid, which is supposed to be maintained at an even 50 or 60 cycles per second, depending on the country, but which tends to drop whenever short-term increases in the load cause the

\section{INTEGRATING WITH A SMART GRID}

There are a number of even more exotic technologies that could become candidates for large-scale energy storage - assuming that researchers can eventually get the cost down to a competitive level. Examples include 'ultracapacitors' that can store huge amounts of electrical charge in atoms-thick layers next to the electrodes, and coils of superconducting wire able to store large amounts of circulating current indefinitely.

But by far the most cost-effective approach to large-scale electric energy storage is to minimize the need for it. That is one of the goals set out earlier this year in the US stimulus bill, which allocated $\$ 4.3$ billion to research and development in renewable-energy generation, energy efficiency and, most especially, a 'smart grid'. Instead of simply adjusting the supply of electricity in response to the vagaries of unpredictable demand, a smart grid would constantly adjust demand as well. When demand hits a elements - such as silicon, iron and aluminium - a battery involves two reactions, one at each electrode, along with an electrolyte that supports the appropriate ion transfer. That makes for a huge and largely untested combination of possible compounds and reactions to search through.

turbines to slow down. Keeping it stable is a challenge for utility companies everywhere.

With that in mind, Beacon Power of Tyngsboro, Massachusetts, has spent the past decade developing a high-tech flywheel that is optimized for frequency regulation. Measuring about 2 metres tall and 1 metre in diameter, the flywheel consists of a cylindrical aluminium core, which houses the motor and generator, and a carbon-fibre composite rim. It is suspended on magnetic bearings inside a vacuum-sealed chamber, where it can spin at up to 16,000 revolutions per minute. The devices are designed to run for 20 years or more with no maintenance, says Matthew Lazarewicz, Beacon's chief technical officer. They can store energy with an efficiency of $85 \%$, he says, and can spin up and down for perhaps millions of cycles during their working life, making them far more durable than batteries.

The challenge now is to bring the cost down, which Beacon hopes to do thanks to a project it has recently undertaken with loan guarantees from the US Department of Energy. In Stephentown, New York, Beacon has begun construction of a \$70-million, 20-MW, 200wheel flywheel farm that will help to regulate

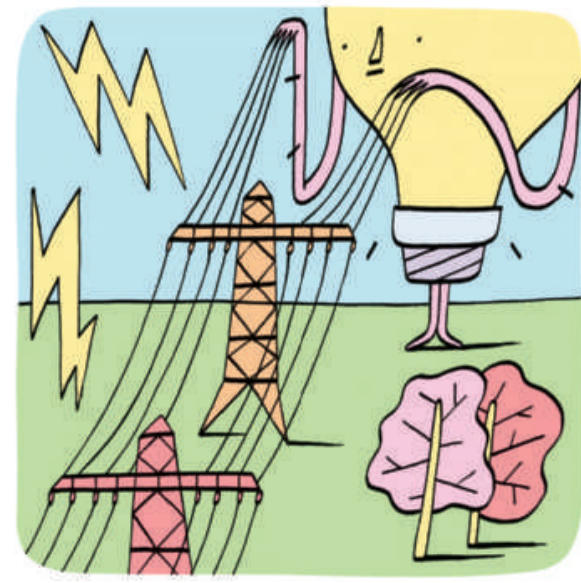

peak, for example, the grid might start cutting power for household refrigerators, office airconditioning systems and other non-urgent uses - just for a moment in each case, and nothing that anyone would notice, but enough
The quest is made feasible, says Sadoway, by supercomputers that can quickly assess proposed battery chemistries, freeing researchers from the need to synthesize and test actual materials. In the coming decade, he says, "I'm optimistic that the rate of discovery will accelerate."

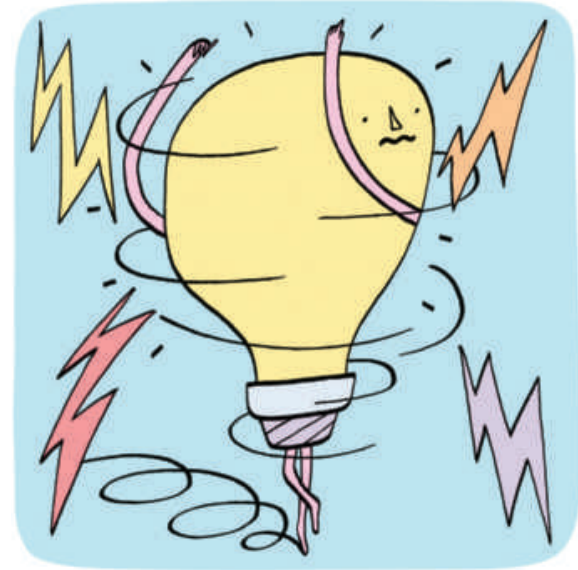

frequency in the regional power grid. The budget includes a number of one-time costs related to establishing its qualifications for the federal loan guarantees. The company estimates that future plants of this size will cost less than $\$ 50$ million - a price it hopes to bring down to about $\$ 30$ million. In late November, the energy department awarded Beacon \$24 million for half the cost of a new 20-MW plant to be built outside Chicago, Illinois.

to smooth out variations in the overall load.

In that kind of system, says Nourai, storage and smart-grid technologies would work together, evening out the usual peaks and troughs in grid load to a greater extent than either could achieve alone. "Variation is never going to go away but with storage it can be much flatter," he says. He sees a future in which even fairly small communities could be "net zero", meaning that on average they make as much electricity as they need, and maintain a reliable supply by exchanging modest amounts of power back and forth with neighbouring communities. Local interconnections would be low-voltage lines, and long-distance highvoltage lines would be needed only to connect wind farms or solar arrays in remote areas with populated regions. That transformation, Nourai says, "will change the way we think about, run and plan" the storage of electricity.

David Lindley is a freelance writer in Alexandria, Virginia. 